\title{
TORTOR BATAK TOBA DALAM KONTEKS PARIWISATA DI MUSEUM HUTA BOLON SIMANINDO KABUPATEN SAMOSIR
}

\author{
F. Kristina Siallagan ${ }^{1}$, Yusnizar Heniwaty ${ }^{2}$, Dilinar Adlin ${ }^{3}$ \\ Prodi Pendidikan Tari/ Fakultas Bahasa dan Seni/ Universitas Negeri Medan \\ Jalan Willem Iskandar Pasar V Medan Estate 20221, Sumatera Utara-Indonesia \\ kristina_siallagan@gmai.com, ${ }^{2}$ yusnizarheni@yahoo.com, ${ }^{3}$ dilinaradlinmpd@gmail.com
}

\begin{abstract}
This Research purposed to figure out the Performance of tortor Batak Toba as one of tourism package of Museum Huta Bolon Simanindo and its impact of increasing tourism visit tothe Museum. The method in this research uses descriptive qualitative method. The population are; the Department of Culture and Tourism Samosir, Museum Huta Bolon Simanindo officers, musicians, dancers, Public figures/Leader, community of Simanindo, and the tourists. The sample was part of the study population. The place of this research was taken in the Museum Huta Bolon Simanindo -Samosir regency. The data collection was done by observation, interviews, documentation and literature study. Generally, it discusses the development of cultural tourism through the performances of tortor Batak Toba which is the potential resources of local communities as cultural attractions. Cultural attractions are expected to have contributed to the preservation of culture in local communities. Tortor performance is held on an open stage in the old village of Huta Bolon. Performanceis no longer sacred but still follow the traditional rules of adatni gondang, such as the number of gondang types, rules of how to ask certain gondang types, the rules of motion in tortor, apparel and equipment. Another packaging of forms of performance that is of short duration and dense, full of variety, imitation of the original forms, and effective cost. Travelers can enjoy the Batak Toba culture, such as music, dance, historical objects, and the feel of Batak Toba villages. Overall the show is divided into two sessions, the first are Tortor Lae-lae, Tortor Mula-mula, Tortor Mula Jadi, Tortor Mangaliat, Tortor Marsiolopolopan, tortor tortor Si Boru Si Doli, and Tortor Pangurason. Performing the second session has been packed in line with its objectives, namely manortor together, Tortor Tunggal Panaluan, and Tortor Si Gale-gale.
\end{abstract}

\section{Keywords: Tortor Batak Toba, Context Tourism}

\section{PENDAHULUAN}

Kabupaten Samosir merupakan salah satu daerah pariwisata yang cukup terkenal di Indonesia. Keindahan alam dan pemandangan serta banyaknya peninggalan-peninggalan bersejarah yang dapat dijadikan sebagai objek wisata. Salah satu objek wisata yang paling banyak dikunjungi oleh para wisatawan adalah Danau Toba. Keindahan Danau Toba dan pemandangan yang terdapat ditempat ini yang menjadi daya tarik para wisatawan dibelahan dunia manapun untuk berkunjung ke Danau Toba. Wisatawan yang datang berkunjung ke tempat ini berasal dari berbagai usia mulai dari anak-anak, remaja, dewasa, orang tua dan lanjut usia. Pada umumnya tempat ini diramaikan oleh wisatawan ketika hari libur umum seperti libur sekolah, hari besar atau tanggal merah.
Tempat wisata yang ada di Samosir sangatlah menarik untuk dikunjungi. Sebab disana terdapat beberapa desa yang menyimpan berbagai macam objek pariwisata yang menarik untuk dinikmati, salah satunya desa Simanindo.Desa Simanindo merupakan salah satu daerah wisata yang terkenal di Kecamatan Simanindo, Kabupaten Samosir. Dari 16 desa yang tercakup dalam wilayah Kecamatan Simanindo, Simanindo salah satu gerbang utama wisatawan ke Kabupaten Samosir. Ke 15 desa lainnya adalah Tomok, Tanjungan, Parbaba, Pardomuan, Parmonangan, Huta Ginjang, Garoga, Tuktuk Siadong, Ambarita, Martopa, Sihusapi, Siallagan, Cinta Dame (Sialapit), Simarmata, dan Dasroha.

Kecamatan Simanindo dikenal sebagai tempat pariwisata yang banyak pengunjungnya, sebab daerah ini memiliki banyak potensi pariwisata, melalui 
keunikan yang ada didesa-desanya. Seperti di Siallagan, ditemukan Batu kursi, di desa Tomok, dengan makam Raja Sidabutar yang sangat tua sekitar 400 tahun, di Tuk-Tuk terdapat bangunan-bangunan hotel yang unik dan mewah berbentuk bangunan Rumah Adat Batak dilengkapi dengan fasilitas yang cukup memuaskan. Selain Pulo Tao, di Simanindo ada objek wisata lain yang cukup berpotensi mengundang wisatawan untuk datang dan menyaksikannya. Objek wisata yang terkenal tersebut dikenal dengan nama Museum Huta Bolon Simanindo yang dijadikan sebagai daerah budaya, tempat berdirinya museum dan pertunjukan tortor Batak Toba.

Di desa Simanindo, tepatnya di kompleks Huta Bolon, tortor Batak Toba dapat ditemukan sebagai sajian bagi wisatawan dengan jadwal yang tetap. Untuk masuk melihat pertunjukan wisatawan akan membayar tiket dengan harga yang sudah ditentukan. Harga tiket tersebut tergolong murah, karena dengan harga $\mathrm{Rp}$. 50.000,- wisawatan dapat menyaksikan 11 tortor Batak Toba. Acara yang dipertunjukkan sudah dikemas dalam kemasan menetap. Tempat pementasan pertunjukan yang diadakan di depan rumah Adat Batak, tepatnya di halaman rumah pemilik patung Sigale-gale ${ }^{l}$, dan acara yang berlangsung mulai dari awal, pertengahan dan akhir sudah menetap. Pada masyarakat Batak Toba, aktivitas manortor $^{2}$ selalu diiringi musik Gondang Sabangunan baik dalam keadaan adat atau religi. Filosofi Batak Toba mengatakan "dimana ada gondang disitu ada tortor”. Ada istilah tektek mula mulani gondang, serser mula mulani tortor (artinya tektek bunyi memulai Gondang, kaki yang bergeser memulai tarian/tortor). Tortor dengan iringan musik Gondang Sabangunan adalah dua hal yang tidak terpisahkan.

\footnotetext{
${ }^{1}$ Sigale-gale : boneka yang terbuat dari kayu dimodifikasi sedemikian rupa sehingga bisa digerakkan dari belakang. ${ }^{2}$ Manortor : Menari
}

Adapun kesebelas tortor Batak Toba tersebut sebagai berikut :

1. Tortor Lae-Lae

2. Tortor Mula-Mula

3. Tortor Mula Jadi

4. Tortor Mangaliat

5. Tortor Marsiolop-olopan

6. Tortor Siboru

7. Tortor Sidoli

8. Tortor Pangurason

9. Manortor bersama

10. Tortor Tunggal Panaluan

11. Tortor Sigale-gale

Pertunjukan Tortor Batak Toba yang disajikan tidak jauh berbeda dengan bentuk pertunjukan aslinya. Dahulu tortor Batak Toba hanya disajikan pada saat upacara atau acara ritual tertentu tetapi saat ini dipertunjukkan untuk hiburan dalam konteks pariwisata. Tortor Batak Toba ini durasinya telah dikemas secara singkat dan padat dari durasi aslinya. Pertunjukan yang ditampilkan menggunakan musik secara langsung dengan memakai Gondang Sabangunan musik tradisional Batak Toba. Acara yang dipertunjukkan penuh variasi mulai dari awal, pertengahan hingga akhir.

Pertunjukan Tortorpada masyarakat Batak Tobamemiliki daya tarik tradisi Batak Toba yang akan menjadi bahasan khusus dalam hal ini, karena perannya dalam peningkatan pariwisata tidak kalah penting bila dibandingkan dengan hal lain sebagai salah satu bentuk budaya yang dimiliki oleh Etnis Batak Toba. Kebudayaan tortor Batak Toba sebagai wujud dari perilaku manusia secara turun temurun dan selalu dipengaruhi oleh norma, adat, kebiasaan yang berlaku dalam suatu kelompok masyarakat. Disadari atau tidak, masyarakat membutuhkan kesenian dalam hidupnya. 
Salah satunya tortor, baik berupa hiburan pribadi, maupun hiburan yang dinikmati secara bersama-sama. Hiburan tersebut dapat dijadikan sebagai kebutuhan diri sendiri atau dapat berguna juga untuk orang lain. Perntunjukan Tortor Batak Toba ini dengan senang hati diterima oleh masyarakat Simanindo dilihat dari tidak adanya kontra pada setiap pertunjukan. Penari dan pemusiknya sekelompok orang tua dan anak muda yang ada di desa Simanindo tersebut.

\section{LANDASAN TEORI}

Untuk membahas Tortor Batak Toba dalam Konteks Pariwisata di Museum Huta Bolon Simanindo penulis menggunakan teori pariwisata dari Soedarsono (1966:33) :

"Dalam mengemas seni pertunjukan sebagai komoditi pariwisata, ada lima ciri yang baik, yakni singkat dan padat, penuh variasi, telah dihilangkan unsur ritualnya, merupakan tiruan bentuk asli, dan murah harganya. Dengan ciri inilah paket-paket tontonan akan menarik bagi wisatawan".

\section{METODOLOGI.}

\section{Lokasi dan Waktu.}

Sesuai dengan judul penelitian "Tortor Batak Toba dalam Konteks Pariwisata di Museum Huta Bolon Simanindo Kabupaten Samosir”, maka lokasi penelitian adalah di desa Simanindo Kecamatan Simanindo Kabupaten Samosir. Waktu yang diperlukan dalam penelitian ini untuk mendapatkan data yang dibutuhkan adalah selama 3 bulan, yang dilaksanakan pada November 2015 - Januari 2016.

\section{Populasi dan Sumpel.}

Populasi dan sampel dalam penelitian ini adalah Dinas dan Kebudayaan Pariwisata Kabupaten
Samosir, Museum Huta Bolon Simanindo, pemain musik, penari, tokoh masyarakat, masyarakat Simanindo, dan wisatawan.

\section{Teknik Pengumpulan Data.}

Teknik pengumpulan data yang dilakukan adalah sebagai berikut :

1. Observasi

2. Wawancara

3. Dokumentasi

4. Studi kepustakaan

Teknik Analisi Data.

Penulis menganalisa dan menguraikan datadata tersebut dengan menggunakan teknik penelitian kualitatif yaitu sebagai prosedur pemecahan masalah yang diselidiki dengan menggambarkan keadaan objek penelitian pada saat sekarang.

\section{HASIL DAN PEMBAHASAN}

\section{Gambaran Umum}

Kabupaten Samosir merupakan sebuah kabupaten yang dimekarkan dari Kabupaten Toba Samosir dan dibentuk berdasarkan Undang-Undang Nomor 36 Tahun 2003 tentang Pembentukan Kabupaten Samosir dan Kabupaten Serdang Bedagai di Sumatera Utara. Pembentukan Kabupaten ini diresmikan pada tanggal 7 Januari 2004 oleh Menteri Dalam Negeri atas Nama Republik Indonesia.Setelah adanya penetapan Samosir sebagai Kabupaten, maka secara administratif ada 9 Kecamatan, 111 Desa, dan 6 Kelurahan dengan Ibukota Kecamatan Pangururan.Kabupaten in terdiri dari 6 Kecamatan yang berada di dalam Pulau Samosir dan 3 Kecamatan lagi berada di daerah lingkar Danau Toba. Kecamatan yang berada di dalam Pulau Samosir yaitu Kecamatan Simanindo, Kecamatan Pangururan, Kecamatan Onan Runggu, Kecamatan Nainggolan, Kecamatan Ronggurnihuta, Kecamatan Palipi, 
sedangkan Kecamatan yang berada di luar Pulau Samosir yaitu Kecamatan Sianjur Mula-Mula, Kecamatan Harian Boho, dan Kecamatan Sitio-Tio.

Luas Kabupaten Samosir secara keseluruhan mencapai 254.715 ha, terdiri dari daratan seluas 144.455 ha dan perairan danau seluas 110.260 ha.Luas dan batas perairandi kawasan Danau Toba belum ada ketentuan yang pasti. Namun mengingat Pulau Samosir tepat berada dan dikelilingi oleh Danau Toba, secara proporsional luas perairan Danau Toba yang menjadi bagian yang terluas dibandingkan dengan enam kabupaten lainnya di sekeliling perairan Danau Toba.

\section{Kemasan Pariwisata}

Pertunjukan tortor Batak Toba di Museum Huta Bolon Simanindo sudah dikemas secara singkat dan padat. Baik dari ragam gerak dan durasi karena mempertimbangkan situasi dan kondisi para pemain, maupun para penonton atau wisatawan. Ragam gerak pada pertunjukan tortor ini pada umumnya sama. Pertunjukan tortor ini juga penuh variasi, dapat dilihat dari segi busananya. Busana yang dipakai sudah memakai kain yang berwarna, bukan hanya sekedar ulos saja. Sortali yang digunakan juga sudah ditempah seperti yang banyak digunakan pada sekarang ini.

Pertunjukan tortor Batak Toba ini telah dihilangkan unsur ritualnya. Mereka lebih bebas, tidak terikat pada waktu, maupun kedudukan setiap peserta pada upacara adat yang sesungguhnya. Pertunjukan tortor Batak Toba ini merupakan tiruan dari bentuk aslinya. Urutan dari jenis gondang dan tortor sudah mengikuti adat ni gondang tetapi unsur ritualnya sudah dihilangkan. Dilihat dari segi harga, dapat dikatakan murah. Di Museum Huta Bolon ini wisatawan dapat menikamati potensi dari budaya Batak Toba, seperti musik, tarian, benda-benda bersejarah, dan nuansa perkampungan Batak Toba. Pada tariannya wisatawan dapat menikmati keseluruhan pertunjukan yang didalamnya berbagai macam ritual Batak Toba.

\section{Tahapan Pertunjukan}

\section{Pembuka}

Pertunjukan tortor di Museum Huta Bolon Simanindo dimulai dengan membawa kerbau ke borotan yang ada di tengah halaman. Tortor Lae-lae menjadi pembuka pada pertunjukan karena tortorini khusus untuk menarik kerbau ke borotan. Pargonsi akan memulai gondang setelah Paminta Gondang mengatakan : “Amang panggual pargonsi nami, bahen haтu majo gondang lae2 asa diboan hami horbo onlaho disangkut hu borotan”. Yang artinya adalah "Bapak pemain musik kami, bunyikanlah Gondang Laelae agar kami bawa kerbau ini untuk diikat ke tonggak". Para penari berbaris dan manortor untuk membawakan kerbau terserbut untuk di ikatkan di tonggak.

\section{Isi}

Isi pada pertunjukan ini adalah sebagai berikut :

1. Tortor Mula-Mula dan Mula Jadi

Pada tortor ini Paminta Gondang akan menyerukan: "Amang Panggual Pargonsi nami, nunga dibahen haти Gondang Lae-lae,bahen haти ma muse Gondang Mula-Mula sahat hu Mula Jadi”. Yang artinya adalah : Bapak pemain musik kami, Gondang Lae-lae telah dibunyikan, sekarang bunyikanlah Gondang Mula-Mula sampai ke Mula Jadi”. Setelah manortor Mula-Mula sampai ke Mula Jadi, kemudian berhenti sejenak dan dilanjutkan dengan Tortor Sahata Mangaliat.

\section{Tortor Sahata Mangaliat}

Pada tortor ini Paminta Gondang akan menyerukan : "Amang Panggual Pargonsi nami, nunga dibahen hamu Gondang Mula-Mula sahat hu Mula Jadi ,bahen hamu ma muse Gondang Sahata Mangaliat". Yang artinya adalah : Bapak pemain musik kami, 
Gondang Mula sahat hu Mula Jadi telah dibunyikan, sekarang bunyikanlah Gondang Sahata Mangaliat". Setelah manortor Sahata Mangaliat, kemudian berhenti sejenak dan dilanjutkan dengan Tortor Marsiolopolopan.

\section{Tortor Marsiolop-olopan}

Pada tortor ini Paminta Gondang akan menyerukan : "Amang Panggual Pargonsi nami, nunga dibahen hamu Gondang Sahata Mangaliat, bahen hamu ma muse Gondang Marsiolop-olopan”. Yang artinya adalah : Bapak pemain musik kami, Gondang Sahata Mangaliat telah dibunyikan, sekarang bunyikanlah Gondang Marsiolop-olopan". Setelah manortor Sahata Mangaliat, kemudian berhenti sejenak dan dilanjutkan dengan Tortor Siboru dan Sidoli.

\section{Tortor Siboru dan Sidoli}

Pada tortor ini Paminta Gondang akan menyerukan : “Amang Panggual Pargonsi nami, nunga dibahen hamu Gondang Marsilop-olopan, bahen hamu ma muse Gondang Siboru dohot Sidoli”. Yang artinya adalah : Bapak pemain musik kami, Gondang Marsiolop-olopan telah dibunyikan, sekarang bunyikanlah Gondang Siboru dan Sidoli”. Setelah manortor Siboru dan Sidoli, kemudian berhenti sejenak dan dilanjutkan dengan Tortor Pangurason.

\section{Tortor Pangurason}

Pada tortor ini Paminta Gondang akan menyerukan: "Amang Panggual Pargonsi nami, nunga dibahen hamu Gondang Siboru dohot Sidoli ,bahen haти та muse Gondang Pangurason”. Yang artinya adalah : Bapak pemain musik kami, Gondang Siboru dan Sidoli telah dibunyikan, sekarang bunyikanlah Gondang Pangurason". Setelah manortor Pangurason, kemudian berhenti sejenak dan dilanjutkan dengan manortor Bersama.

\section{Manortor Bersama}

Pada bagian ini, ada tiga bagian tortor yang diadakan yaitu tortor Mangaliat, tortor Marsiolopolopan dan tortor Hasahatan Sitio-tio. Penyampaian kepada Paminta Gondang sama dengan sebelumnya. Setelah manortor bersama, kemudian berhenti sejenak dan dilanjutkan dengan Tortor Tunggal Panaluan.

\section{Tortor Tunggal Panaluan}

Pada tortor ini Paminta Gondang akan menyerukan : "Amang Panggual Pargonsi nami, nunga dibahen hamu Gondang Tunggal Panaluan. Yang artinya adalah : Bapak pemain musik kami, bunyikanlah Gondang Tunggal Panaluan. Setelah manortor Tunggal Panaluan, kemudian berhenti sejenak dan dilanjutkan dengan Tortor Sigale-gale.

\section{Penutup}

Diakhir pertunjukan adalah Gondang Sigalegale yang bertujuan untuk memberikan kesempatan kepada wisatawan datang ke depan memberikan sumbangan. Pada tortor ini Paminta Gondang akan menyerukan : “Amang Panggual Pargonsi nami, nunga dibahen hamu Gondang Pangurason, bahen hamu ma muse Gondang Sigale-gale”. Artinya adalah : Bapak pemain musik kami, Gondang Pangurason telah dibunyikan, sekarang bunyikanlah Gondang Sigalegale".

Dari keseluruhan tortor yang disajikan pada pertunjukan ini, dapat dilihat bahwa sesungguhnya ragam gerak yang ada pada setiap tortor semuanya sama hanya ada beberapa tortor yang berbeda. Pengembangan tortor ini tidak jauh berbeda, hanya terdapat pada pola lantai. Walaupun pertunjukan tortor ini disajikan dalam kemasan pariwisata namun pola tradisi tidak pernah mereka tinggalkan. Dibuktikan dengan setiap awal tortor harus dimulai dengan somba, untuk ragam geraknya selanjutnya sudah ada kebebasan pada 
koreografer untuk merubah, baik pola lantai maupun ragam gerak. Namun, pada dasarnya ragam gerak yang dilakukan tidak jauh beranjak dari tradisi Batak Toba. Selain itu, yang unik dari mereka adalah mereka tidak berpatok terhadap hitungan tetapi mereka mengikuti ritme dari gondang. Kemudian penarilah yang menentukan berhentinya gondang melalui Raja Parhata. Durasi dari pertunjukan tortor ini terkadang dapat berubah apabila penonton semangat menyaksikan pertunjukan, otomatis pertunjukan akan semakin panjang. Kalau penonton semangat, penari akan semangat untuk menari dan akan menari semakin lama.

\section{PENUTUP}

\section{Kesimpulan}

Berdasarkan uraian bab terdahulu akhirnya penulis mengambil kesimpulan sebagai berikut :

1. Pertunjukan tortor Batak Tobadi Museum Huta Bolon Simanindo dilaksanakan pada panggung terbuka dalam perkampungan tua. Di Museum Huta Bolon ini wisatawan dapat menikamati potensi dari budaya Batak Toba, seperti musik, tarian, benda-benda bersejarah, dan nuansa perkampungan Batak Toba. Pada tariannya wisatawan dapat menikmati keseluruhan pertunjukan yang didalamnya berbagai macam ritual Batak Toba.

2. Seni pertunjukan tortor tidak sakral lagi walaupun masih mengikuti aturan adat $n i$ gondang. Pertunjukan sudah mengalami perubahan, walaupun masih terikat pada adat $n i$ gondang seperti, jumlah jenis gondang harus ganjil, aturan meminta jenis gondang, aturan gerak dalam tortor, pakaian dan peralatan. Secara keseluruhan pertunjukan dibagi dua sesi. Sesi pertama, masih mengikuti sebagian besar adat ni gondang tetapi nilai kesakralannya sudah dihilangkan. Jenis tortor yang disajikan pada sesi pertama adalah tortor Lae-lae, tortor Mula-mula, tortor Mula Jadi Tortor Mangaliat, tortor Marsiolop-olopan, tortor Si doli, tortor Si boru, tortor Pangurason. Pertunjukan sesi kedua sudah dikemas sesuai tujuannya disajikan kepada wisatawan. Jenis tortor yang disajikan adalah manortor bersama, , tortor Tunggal Panaluan, dan tortor Si gale-gale.

3. Pertunjukan tortor murni hasil inisiatif Yayasan Huta Bolon yang didirikan Raja Humpul Panel (RPH) Sidauruk. Sedangkan pemerintah daerah dan industri pariwisata yang telah memanfaatkan pertunjukan seni tersebut dalam mendapatkan penghasilan asli daerah (PAD) dan menggerakkan usaha jasa, belum memberikan kontribusinya secara maksimal.

4. Pertunjukan tortor disesuaikan dengan situasi dan kondisi kehidupan para seniman, serta keterbatasan waktu para wisatawan. Durasi waktu pertunjukan disesuaikan agar penonton tidak sampai bosan. Tempat dan panggung pertunjukan sama seperti pelaksanaan upacara sungguhan agar menimbulkan kesan sebagai tiruan dan alami. Jumlah pemain sangat terbatas sehingga menuntut keprofesionalan para seniman melaksanakan peran yang berbeda pada setiap tortor dengan tidak merubah pakaian dan peralatan.

\section{SARAN}

Agar para wisatawan yang berkunjung ke Pulau Samosir memperolehkesan yang baik dan memuaskan sehingga setelah mereka kembali ke Negara asalnya masing-masing, merekaakan bercerita kepada keluarga ataupun teman-temannya atas kesan yang baikyang diperolehnya selama berada pada objek yang 
dikunjunginya, dan mereka ingin kembali datang untuk kedua kalinya. Untuk itu penulis mencobamemberikan saran yang mungkin berguna untuk kemajuan dan perkembanganpariwisata di Kabupaten Samosir.Dalam pengembangan ini hendaknya :

1. Pemerintah daerah memberikan bimbingan dan penyuluhan tentang materi pelayanan pariwisata sehingga berdampak positif dalam pengembangan pariwisata.

2. Pertunjukan tortor di Huta Bolon Simanindo sudah perlu menggunakan pemandu pertunjukan bukan bagian dari panortor dan pargonsi. Pemandu pertunjukan harus dapat menciptakan suasana lebih bermakna dan hidup,serta memberikan penjelasan jika ada diantara wisatawan yang merasakurang jelas.

3. Pengembangan pariwisata di Kabupaten Samosir perlu mengubah strategi, yaitu dengan menerapkan program pariwisata budaya berbasis kerakyatan. Artinya masyarakat lokal mempunyai peran dan berinisiatif memberikan pelayanan.

\section{DAFTAR PUSTAKA}

Adha Sutrisno Situmorang, 2013. Potensi Objek Wisata di Kabupaten Samosir. Medan.

Erwin Pardede, 2012. Peranan Musik tradisional Batak Toba dalam Peningkatan Pariwisata di Daerah Parapat Kabupaten Simalungun. Medan.

Ester Debora S, 2012. Gondang Sabangunan pada Tortor Sigale-gale di Desa Tomok Kecamatan Simanindo Kabupaten Samosir. Medan.

Evanny Romas Sitio, 2011. Seni Pertunjukan Tortor dan Gondang Sabangunan di Huta Bolon sebagai Atraksi Wisata, Medan : Fakultas Sastra USU.

Hadeli, 2006. Metode Penelitian Kuantitatif. Jakarta: Kencana.
Hidayat, 2007. Metode Penelitian Kuantitatif. Jakarta.

Hutasoit. 1979. Komunikasi Batak. Jakarta : Bumi Aksara.

Hutajulu, Rithaony. 1997. Dampak Pariwisata Terhadap Upacara Tradisional pada masyarakat Batak Toba. Bandung : Masyarakat Seni Pertunjukan Indonesia.

Joni Sihite, 2013. Motivasi Wisatawan Domestik untuk Melakukan Kunjungan Rekreasi di Objek Lumban Silintong Kecamatan Balige Kabupaten Samosir. Medan.

Lerin R Sihotang, 2014. Bentuk dan Penyajian Musik Gondang Mangaliat dalam Upacara Adat Panagkok Saring-Saring di Desa Sabulan Kecamatan Sitio-tio Kabupaten Samosir. Medan.

Maryaeni. 2005. Metode Penelitian Kebudayaan. Jakarta : Bumi Aksara.

Pendit, Nyoman S. 1999. Ilmu Pariwisata Sebuah Pengantar Perdana. Jakarta : Pradnya Paramita.

Riantiarno (1998), Seni dan Pariwisata (Makalah), Jakarta : Departemen Seni dan Pariwisata.

Soedarsono, 1966. Pengantar Pengetahuan Tari. Yogyakarta: Asti.

Sugiyono, 2008. Metode Penelitian Kuantitatif dan $R \& D$. Bandung : Alfabeta.

Sugiyono, 2009. Metode Penelitian Kuantitatif dan $R \& D$. Bandung : Alfabeta.

Supranto, 2004. Metodologi Penelitian Kependidikan. Bandung: Publishing House.

Supriyono, Arif E (1992), Tari untuk Pariwisata: Koreografi Padat, Atractive dan Berwawasan Lingkungan, Jurnal Penciptaan Tari, Yogyakarta : Institut seni Indonesia (ISI).

Spillane, James J. 1982. Ekonomi Pariwisata, sejarah, dan prospeknya. Yogjakarta : Kanisius. 